\title{
What is the current status of Japan's efforts to meet global goals and targets to eliminate cervical cancer?
}

\author{
Rei Haruyama*, Hiromi Obara, Noriko Fujita \\ Bureau of International Health Cooperation, National Center for Global Health and Medicine, Tokyo, Japan.
}

\begin{abstract}
Following the global call to action by the World Health Organization (WHO), the world is currently moving to eliminate cervical cancer as a public health problem. To eliminate the cancer within this century, which is defined as an age-adjusted cervical cancer incidence rate (ASIR) below 4 per 100,000 women, WHO recommends all countries to achieve "90-70-90" targets for human papilloma virus (HPV) vaccination, cervical cancer screening, and treatment of precancer and cancer by 2030. In Japan, ASIR has been rising since the late 1990s to 11.1 per 100,000 women, and this rise is particularly prominent in women of reproductive age. HPV vaccination coverage is as low as $0.3 \%$, largely due to the Government's ongoing suspension of proactive recommendations for the vaccine. Given the absence of centralized, population-based cervical cancer screening program and a nationwide surveillance system for systematic monitoring, the exact screening participation rate and treatment rate are difficult to estimate. A national survey suggested that only around $40 \%$ of women between the ages of 20 and 69 years underwent cervical cancer screening within the last two years. National policies and systems for HPV vaccination and screening should be updated in a more efficient way as new evidence and innovations become available. In the wake of powerful global momentum, actions must be taken now to further enhance cervical cancer control and ensure that Japanese girls and women are no longer left behind.
\end{abstract}

Keywords: cervical cancer control, monitoring, WHO Global Strategy

\section{Introduction}

Cervical cancer is one of the few cancers that is preventable with established interventions at both the population and individual levels. In May 2018, the Director-General of the World Health Organization (WHO) announced a global call to action to eliminate cervical cancer and called for all stakeholders to unite behind this common goal (1). Just recently in August 2020, the WHO Global Strategy to Accelerate the Elimination of Cervical Cancer as a Public Health Problem was adopted by the WHO Member States, which defines the goal of elimination as an agestandardized incidence rate (ASIR) below 4 per 100,000 women-years (1). To achieve this goal within the 21 st century, the Strategy recommends concomitant attainment of "90-70-90" targets by 2030: i) $90 \%$ of girls fully vaccinated with human papilloma virus (HPV) vaccine by 15 years of age, ii) $70 \%$ of women screened using a high-performance test by 35 and again by 45 years of age, and iii) $90 \%$ of women identified with cervical precancer or cancer are treated. These "90-7090" are global targets that all countries should aim for, including Japan. What is the current status of Japan's efforts to meet global goals and targets to eliminate cervical cancer?
Age-standardized cervical cancer incidence rate (goal: below 4 per 100,000 women)

According to the most recent national cancer registry data of Japan, there were 11,012 new cases of cervical cancer in 2017 (2). This corresponds to an ASIR of 11.1 per 100,000 women, which is higher than the estimate for high-income countries (8.3 per 100,000 women) (3). Data further show that the ASIR decreased from the 1980s until the late 1990s, but it has increased since then (2). The rise is particularly prominent in women in their 20-30s (Figure 1) (2).

HPV vaccination coverage by 15 years of age (target by 2030: 90\%)

Bivalent and quadrivalent HPV vaccines have been included in Japan's national immunization program for girls ages 12-16 years. However, following media reports of girls having various symptoms such as chronic pain and motor impairment after vaccination, the Ministry of Health, Labour, and Welfare (MHLW) suspended proactive recommendations for the vaccine in June 2013 (4). HPV vaccine is still being provided for free to girls and parents seeking vaccination, but individuals are not approached with informational 
materials. Over the last seven years, large-scale epidemiological studies in Japan indicated the effectiveness and safety of the vaccine (5-7). Medical consultations and facilities for patients concerned about symptoms after vaccination have been instituted in every prefecture (8). Nevertheless, due to the MHLW's ongoing suspension of recommendations, confusion over vaccination remains among the general population and the estimated vaccination coverage has stagnated at a low level $(<1 \%)$, in contrast to Mexico, the Cook Islands, Portugal, and the Seychelles, which have already attained the $90 \%$ target (Figure 2) (9).

Participation rate in cervical cancer screening using a high-performance test by 35 and by 45 years of age (target by 2030: 70\%)

Cervical cancer screening using cytology started relatively

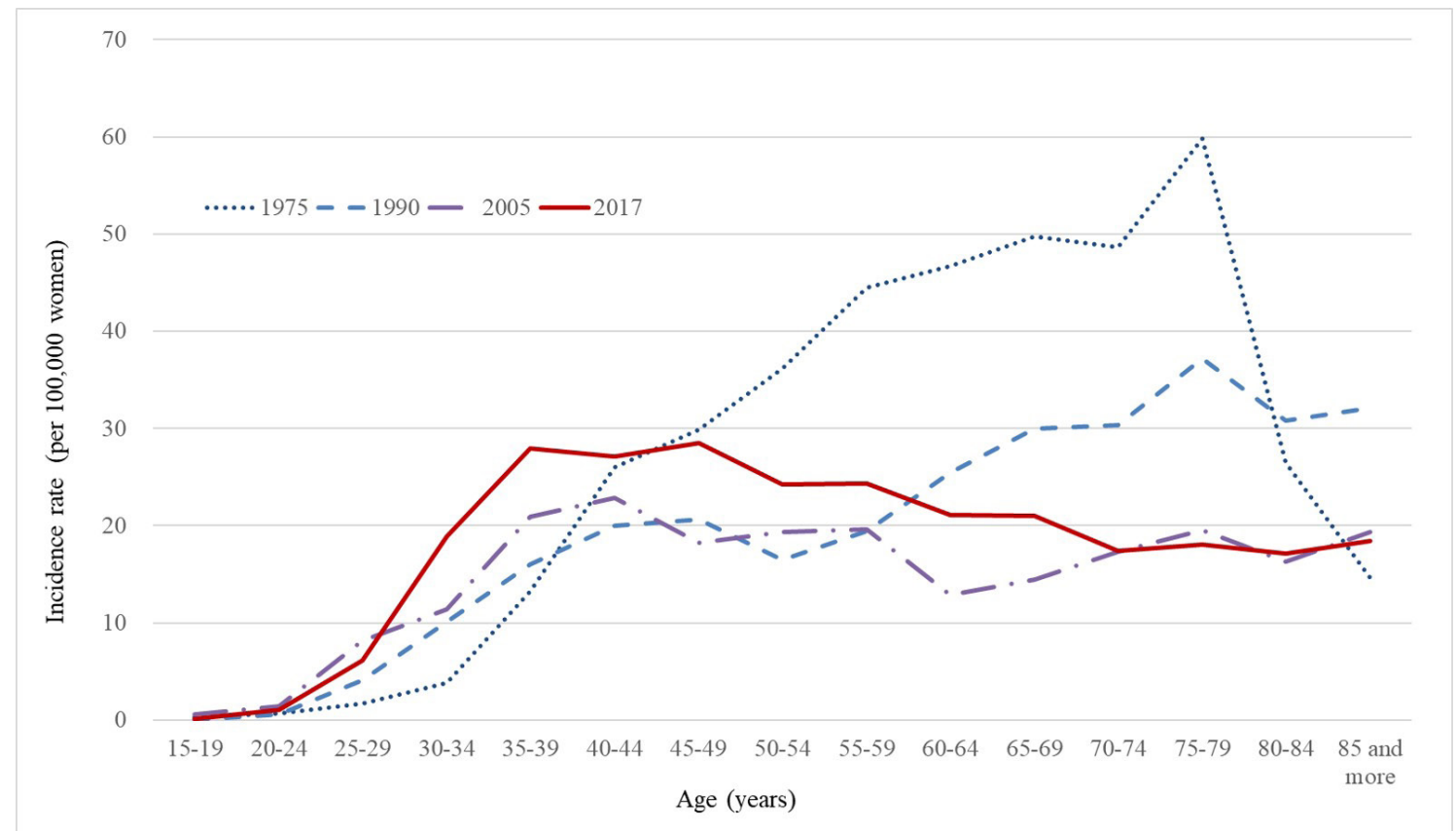

Figure 1. Cervical cancer incidence by age group in 1975, 1990, 2005, and 2017. Data source: National estimates from regional population-based cancer registries 1975-2015, National cancer registry 2016-2017 (2).

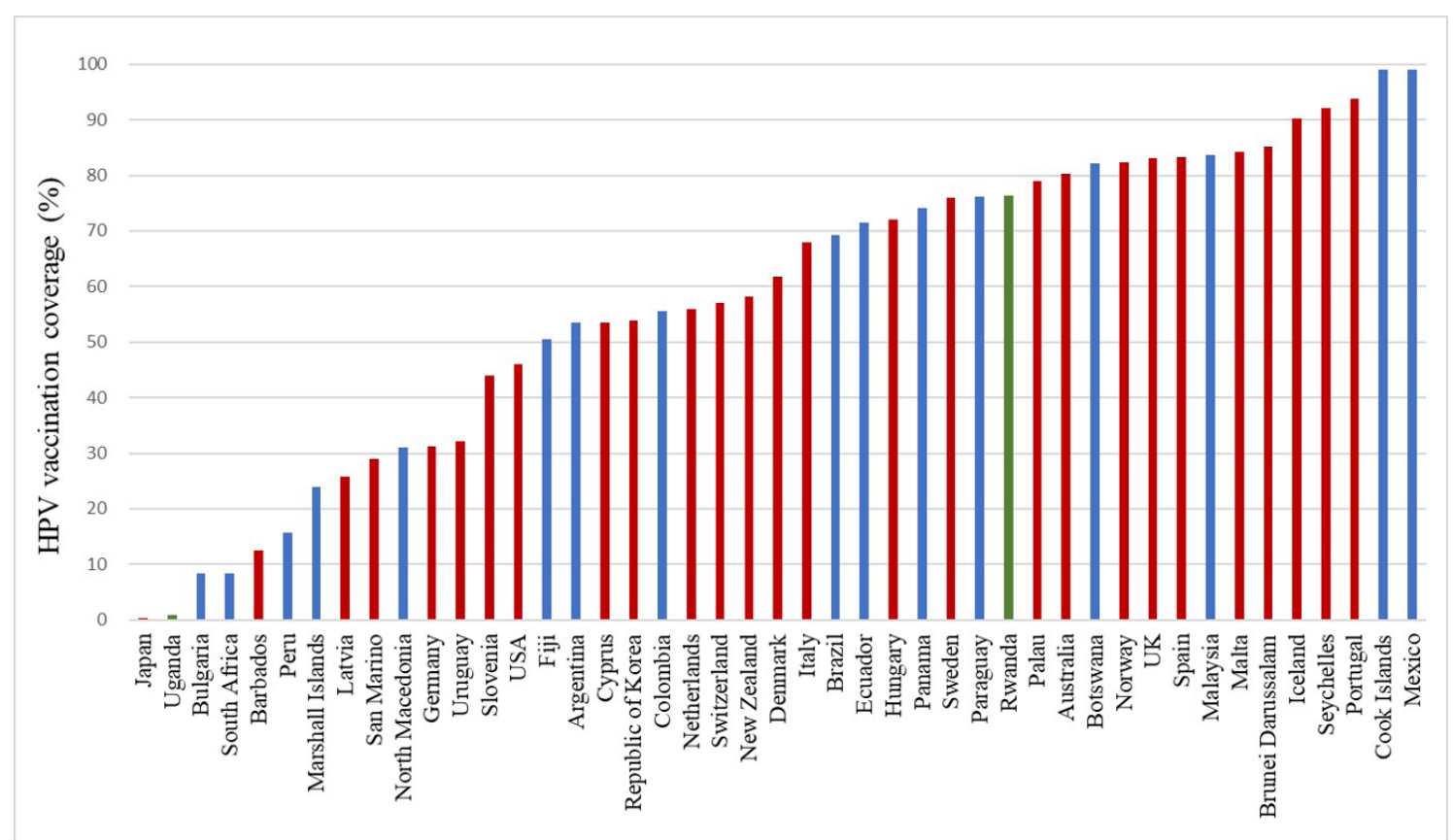

Figure 2. Estimated coverage of girls fully vaccinated with HPV vaccine by 15 years of age. Based on the World Bank's classification of income levels in 2019, red indicates high-income countries, blue indicates middle-income countries, and green indicates low-income countries. Data source: WHO estimates of human papillomavirus immunization coverage 2010-2018 (9). 
early on, in around the 1960s, in Miyagi Prefecture (10). The screening program was subsequently expanded nationwide in 1983 for women ages 40 years and over under the Health and Medical Service Act for the Elderly. However, 15 years later in 1998, the MHLW transferred the responsibility for screening to the prefectural and municipal levels for economic reasons (11). Since then, Japan has not had a centralized, population-based cervical cancer screening program, although women have several opportunities to undergo screened for cervical cancer, including at organized screening programs run by municipalities and opportunistic screening offered by employers, by insurers, or in clinical settings. The cervical screening program run by municipalities uses conventional or liquid-based cytology and varies widely in program management (e.g. call-and-recall system), quality, and cost (11). In addition, the exact participation rate is unknown due to the absence of a nationwide surveillance system to systematically monitor screening. A national questionnaire-based survey conducted in 2019 suggests that only $43 \%$ of women between the ages 20 to 69 years underwent cervical cancer screening within the last two years, and this rate has remained at that level over the last six years (12). The most common reasons why some women do not undergo screening are that they do not have time, they are confident that they are healthy and do not feel the need to be screened, and they feel that they can always seek medical attention if necessary (13).

\section{Treatment rates of cervical precancer and cancer (target by 2030: 90\%)}

Treatment rates are also very difficult to estimate in the absence of a systematic monitoring system. A report on 4.3 million cytology samples collected in 2017 during cervical cancer screening done in municipalities found that 85,426 samples required further testing, but $25 \%$ were lost to follow-up (14). With a universal health insurance system and easy access to gynecologists, women requiring follow-up may have undergone further testing and treatment without notifying municipalities (11). However, there is no system to obtain this information. The treatment rate for women diagnosed with cancer is also unknown, although the survival rate for invasive cervical carcinoma that was managed appropriately is relatively high. The most recent report has indicated that the 5-year survival rates for the International Federation of Gynecology and Obstetrics (FIGO) 2009 stage I, II, III and IV carcinomas are $93.1 \%, 75.9 \%, 59.1 \%$ and $31.2 \%$, respectively (15).

\section{The way forward in Japan}

As shown here, Japan faces multiple challenges in monitoring and achieving the goal and "90-70-90" targets for elimination of cervical cancer. Recently, however, signs of progress have become apparent. One is the regulatory approval of the nonavalent HPV vaccine in July 2020. Expectations are that this vaccine will be widely used, as it would cover $84 \%$ of the types of HPV that cause cervical cancer in Japan (16). Resumption of proactive recommendation of vaccination by the MHLW and increased public confidence in the vaccine will nevertheless be required to increase coverage. A modeling study predicted that gradual, if not immediate, restoration of HPV vaccination coverage to $70 \%$ in 12 -year-olds over the period $2020-2025$ could prevent 32,000-36,900 new cases of cervical cancer over the next 50 years in Japan (17). Colombia and Denmark have once faced a similar HPV vaccination crisis, and their experiences indicate that coverage can be restored with a strong political will (18). Another is the publication of updated evidence-based cervical cancer screening guidelines (19). The guidelines now recommend physician-sampled HPV DNA testing as the primary method for screening, in addition to cytology. This will allow the screening interval to be extended to five years for HPV-negative women; if started at age 30 and ended at age 60 , women would only need to undergo screening seven times at a minimum. The optimal follow-up for HPV-positive women and the applicability of self-sampled HPV DNA testing in Japan are currently being studied further (19). In any event, additional efforts should be made at the national and local levels to increase the participation rate as well as to implement a surveillance system to systematically monitor participation, follow-up, and treatment rates.

\section{Conclusion}

At the global level, some countries are moving at a fast pace to attain the "90-70-90" targets by 2030 in collaboration with various actors and stakeholders such as professional societies, patient advocacy groups, the private sector, United Nations organizations, and nongovernment organizations. Japan is a leader of the call for universal health coverage and the creation of a world where "no one is left behind" (20). Ironically, it is currently Japanese girls and women who are left behind. It is time for actions to be taken to further enhance cervical cancer control.

\section{Funding: None}

Conflict of Interest: The authors have no conflict of interest to disclose.

\section{References}

1. World Health Organization. Cervical cancer. https://www. who.int/health-topics/cervical-cancer (accessed August 12, 2020). 
2. Cancer Registry and Statistics. Cancer Information Service, National Cancer Center, Japan (Ministry of Health, Labour, and Welfare) https://ganjoho.jp/reg_stat/ statistics/dl/index.html\#incidence (accessed August 12, 2020).

3. International Agency for Research on Cancer. Global Cancer Observatory (GLOBOCAN) 2018 Estimates. http://gco.iarc.fr (accessed August 12, 2020).

4. The Ministry of Health, Labour, and Welfare, Japan. https://www.mhlw.go.jp/bunya/kenkou/kekkakukansenshou28/pdf/kankoku_h25_6_01.pdf (accessed August 12, 2020). (in Japanese)

5. Suzuki S, Hosono A. No association between HPV vaccine and reported post-vaccination symptoms in Japanese young women: results of the Nagoya study. Papillomavirus Research. 2018; 5:96-103.

6. Matsumoto K, Yaegashi N, Iwata T, Yamamoto K, Nagashima M, Saito T, Ushijima K, Takahashi F, Noda K, Yoshikawa $\mathrm{H}$. Early impact of the Japanese immunization program implemented before the HPV vaccination crisis. Int J Cancer. 2017; 141:1704-1706.

7. Ueda Y, Yagi A, Nakayama T, Hirai K, Ikeda S, Sekine M, Miyagi E, Enomoto T. Dynamic changes in Japan's prevalence of abnormal findings in cervical cytology depending on birth year. Sci Rep. 2018; 8:5612. Erratum in: Sci Rep. 2018; 8:13384.

8. Japanese Medical Association, Japanese Association of Medical Science. Guide to medical treatment for symptoms arising after HPV vaccination $h t t p: / / d l . m e d$. or.jp/dl-med/teireikaiken/20150819_hpv.pdf (accessed August 12, 2020). (in Japanese)

9. World Health Organization. WHO estimates of human papillomavirus immunization coverage 20102018 (version date: 2019/7/18) https://www.who.int/ immunization/monitoring_surveillance/data/en/(accessed August 12, 2020).

10. Hamashima C, Aoki D, Miyagi E, Saito E, Nakayama T, Sagawa M, Saito H, Sobue T; Japanese Research Group for Development of Cervical Cancer Screening Guidelines. The Japanese guideline for cervical cancer screening. Jpn J Clin Oncol. 2010; 40:485-502.

11. Sauvaget $C$, Nishino $Y$, Konno R, Tase T, Morimoto T, Hisamichi S. Challenges in breast and cervical cancer control in Japan. Lancet Oncol. 2016; 17:e305-e312.

12. 2019 Comprehensive survey of living conditions. https:// www.mhlw.go.jp/toukei/list/20-21.html (accessed August 12, 2020). (in Japanese)

13. Public opinion survey on cancer control and tobacco control. https://survey.gov-online.go.jp/r01/r01gantaisaku/2-1.html (accessed August 12, 2020). (in Japanese)

14. Report on regional public health services and health promotion services https://www.mhlw.go.jp/toukei/list/3219.html (accessed August 12, 2020). (in Japanese)

15. The 61th annual treatment report of the Gynecologic Oncology Committee, Japan Society of Obstetrics and Gynecology. http://plaza.umin.ac.jp/ jsog-go/new5.html (accessed August 12, 2020). (in Japanese)

16. Miura S, Matsumoto K, Oki A, Satoh T, Tsunoda H, Yasugi T, Taketani Y, Yoshikawa H. Do we need a different strategy for HPV screening and vaccination in East Asia? Int J Cancer. 2006; 119:2713-2715.

17. Simms KT, Hanley SJB, Smith MA, Keane A, Canfell $\mathrm{K}$. Impact of HPV vaccine hesitancy on cervical cancer in Japan: a modelling study. Lancet Public Health. 2020; 5(4):e223-e234.

18. World Health Organization. Denmark campaign rebuilds confidence in HPV vaccination. https://www.who.int/ features/2018/hpv-vaccination-denmark/en/ (accessed August 12, 2020).

19. National Cancer Center, Japan. Updated cervical cancer screening guidelines http://canscreen.ncc.go.jp/ shikyukeiguide2019.pdf (accessed August 12, 2020). (in Japanese)

20. Prime Minister of Japan and His Cabinet. Statement by Prime Minister Abe at "World Leaders for Universal Health Coverage (UHC): A High-Level Discussion at the United Nations on Achieving the SDGs through Health for All" at the Side Event to the 72nd Session of the United Nations General Assembly. September 19, 2017. https://japan.kantei.go.jp/97 abe/ statement/201709/_00013.html (accessed August 12, 2020).

Received August 12, 2020; Revised September 17, 2020; Accepted September 23, 2020

Released online in J-STAGE as advance publication September 30, 2020.

*Address correspondence to:

Rei Haruyama, Bureau of International Health Cooperation, National Center for Global Health and Medicine, 1-21-1 Toyama, Shinjuku-ku, Tokyo 162-8655, Japan.

E-mail: rharuyama@it.ncgm.go.jp 